\title{
FUNÇÕES AXIOLÓGICAS DO RECORTE E DA DISCRETIZAÇÃO DOS OBJETOS DO MUNDO ${ }^{1}$ \\ AXIOLOGICAL FUNCTIONS OF SEGMENTATION AND DISCRETIZATION OF WORLD OBJECTS
}

\author{
Francisco Alves Filho*
}

\begin{abstract}
Resumo: O propósito deste artigo é discutir o papel dos processos referenciais para promover a discretização e a categorização dos objetos dos diversos mundos ao tempo em que os transforma em objetos de discurso. A investigação exigiu um retorno à noção de extensão para poder operar um deslocamento teórico e tratá-la como um fenômeno enunciativo. Assim, a tese de base do trabalho é a de que a operação de discretização e categorização do mundo são motivadas pelas avaliações axiológicas dos sujeitos e gera, sobretudo, uma refração de tais objetos, uma vez que um mesmo objeto pode ser recortado de diversos modos, desde que motivados por intuitos discursivos diversos. A análise oferece indícios bastante relevantes para se pensar que a relação entre objeto do mundo e objeto de discurso, muito longe de ser biunívoca e vericondicional, é de cunho marcadamente socioideológico.
\end{abstract}

Palavras chave: referência; categorização; editorial; apreciação axiológica.

1 Este trabalho teve o apoio financeiro da FAPEPI/CNPq (processo n. 20203.0484/2008).

* Professor do Departamento de Letras da UFPI. E-mail: chicofilhoo@gmail.com. 
ALVES FILHO, F. Funções axiológicas do recorte...

\section{Introdução}

Os estudos sobre referenciação alcançaram um desenvolvimento bastante considerável, principalmente do ponto de vista teórico, o que fez com que muitas teses de base fossem repensadas e redimensionadas (por exemplo, a tese da vericondicionalidade de Frege (1898) e a da anáfora estrita de Milner (2003)). Tal redimensionamento possibilitou que se observasse como os objetos dos mundos são recortados e discretizados, mas entendendo que este recorte e esta discretização constituem processos de fabricação do próprio objeto ou de construção do objeto de discurso (cf. MONDADA \& DUBOIS, 2003). Com isso, afirmou-se centralmente que o ato de referir é um processo caracteristicamente socioideológico, porque motivado por valorações e ao mesmo certificador e legitimador destas valorações. Tendo em conta o que acertadamente afirmou Blikstein (1990), ou seja, que o referente é fabricado segundo os nossos óculos sociais, eu gostaria de me dedicar a alguns dos processos de fabricação dos referentes vinculados às ações ideológicas de recorte-discretização de objetos concretos, sujeitos e instituições.

Nossa discussão aqui toma por base alguns posicionamentos gerais a respeito dos processos referenciais:

a) Inexiste relação biunívoca entre categorias linguísticas e modos de recorte dos objetos de mundo (cf. ILARI, 2001).

b) Os modos de recortar os objetos de mundo produzem uma significativa refração do mundo real, com isso ocorrendo em função de propósitos retóricos.

c) Compreender os recortes dos objetos do mundo quando transformados em objetos de discurso exige um trabalho de interpretação que necessita levar em conta as predicações produzidas a respeito de tal objeto, o gênero de discurso no qual o recorte aparece, o tipo de avaliação axiológica produzida e o discurso geral veiculado no enunciado (cf. ALVES FILHO, 2008). Ou seja, trata-se de uma tarefa analítica e interpretativa extremamente complexa.

d) Indagar-se a respeito da extensão dos objetos de discurso leva inevitavelmente a um trabalho inferencial extremamente importante pelo fato de orientar o interlocutor a se indagar a respeito dos modos como os usuários da linguagem, interessadamente, estabelecem relações entre a linguagem e o mundo (cf. MARCUSCHI, 2005; KOCH, 2001, 2005). 


\section{Recorte e discretização de referentes}

Eu gostaria de mencionar inicialmente o problema diretamente relacionado a um recorte literal e empírico, mas nem por isso menos ideológico, que é o recorte do boi para fins de comercialização da carne. Em muitas cidades do interior do Norte e Nordeste do Brasil, ainda hoje quando se vai ao açougue comprar carne, o magarefe pergunta: $O$ senhor vai querer carne de primeira ou de segunda?, indicandonos claramente a existência de duas categorias disponíveis e consolidadas linguisticamente para a escolha o recorte do boi naquela situação de compra e venda do produto. O critério para a categorização, neste caso, é de caráter monetário, uma vez que estas duas categorias indicam dois preços existentes. Contudo, se vamos a um moderno supermercado, teremos em torno de 20 opções de tipos de carne, com seus correlatos vinte preços diferenciados. Temos aí um mesmo objeto de mundo, mas diferentes objetos de discurso.

Podemos encontrar ainda exemplos de natureza parecida. Quando meu pai era criança, as pessoas, quanto ao comportamento, se dividiam em duas grandes categorias: os normais e os loucos, enquanto as pessoas velhas, salvo exceções, cabiam apenas na categoria caduco. Hoje elas são categorizadas segundo uma miríade de tipos ou "tribos". Olhando um site de psicologia na internet me deparei com uma enorme hiper-categorização para o tipo adolescente, entre os quais se incluem adolescente anoxérico, adolescente artista, adolescente belicista, adolescente celibatário, adolescente combatente armado, adolescente egoísta, adolescente desinformado, adolescente internauta, adolescente indeciso, adolescente irresponsável. Vou parar por aqui porque a lista é grande demais, mas já dá para perceber como tal categorização visa conferir um status tipológico a características que podem ser imensamente circunstanciais, como desinformado e indeciso. Há a pretensão de estabilizar traços comportamentais, os quais podem ser instáveis e circunstanciais, recorrendo à estabilização linguística, ou seja, é como se, pelo fato de dispor de um rótulo linguístico para um comportamento, estivéssemos diante de um problema específico, o qual precisa ser tratado por profissionais também específicos.

Se formos a uma loja virtual de venda de CDs e pusermos a opção estilo de música, também teremos à frente uma discretização e um recorte extremamente subespecificado, muitos dos ritmos inclusive desconhecidos de grandes contingentes de pessoas. Somente para o estilo rock, há uma diversidade muito grande, incluindo algumas subespécies como Classic Rock, Acid Rock, Garage Rock, 
ALVES FILHO, F. Funções axiológicas do recorte...

Blues Rock, British Blues Rock, British Invasion, Folk Rock, Glam Rock, Prog Rock, Kraut Rock, Southern Rock, Hard Rock, Guitar Rock, Heavy Metal, Funk Metal, Hair Metal, Industrial Metal, Grindcore, Rap Core, Thrash, Death Metal, Black Metal, Doom Metal, Speed Metal, Punk Rock, 77 Style Punk, Cow Punk, Hardcore Punk, Emo, NY Hardcore, Oi!, Pop Punk. Esta profusão de espécies nos leva a indagar se haveria traços sonoros, rítmicos e ou melódicos, ou seja, marcadamente técnicos, que presidem as diferenciações entre os subtipos. A julgar pelos modificadores, há fortes indícios de que não se trate de uma categorização de teor técnico, visto que há especificações de variados critérios. O que pode ocorrer é um processo circular: uma música será de um certo tipo porque está categorizada como sendo de um certo tipo, o que se pareceria com um ato batismal tal qual o que ocorre com o nome de pessoas.

Tomemos agora, mas vendo-o por outro prisma, um dos exemplos clássicos para análise da categorização: o caso das cores. Atualmente, se formos a uma loja de tintas, e quisermos comprar um azulejo, o vendedor nos mostrará uma profusão de cores enorme, com subespecificações muito minuciosas. Já vai longe a ideia de que existiriam apenas 3,5 ou 7 cores, a depender da língua e da cultura da qual faziam parte os falantes. Para dar um exemplo, somente nas tonalidades vermelha e amarela, existem muito mais do que sete cores. No caso do recorte-discretização das cores, chama a atenção o fato de que elas são recortadas de modo diferente em função dos propósitos que estão em jogo. Esses propósitos definem um conjunto de critérios que passam a orientar uma maior ou menor quantidade de cores e os tipos de associação semântica. Analisando um site de tintas para interiores de imóveis (http://www.icipaints.com/colourtools/br/css/schemer.html?imagecode= Kitchen_004), podemos observar a existência de um recorte extremamente minucioso (encontramos 41 tipos somente de vermelho, como pode ser visto no quadro seguinte). 


\begin{tabular}{|l|l|l|}
\hline \multicolumn{2}{|c|}{ Cores da família do vermelho } \\
\hline Toque de ameixa & Segredo & Vermelho escuro vibrante \\
Framboesa silvestre & Baile de máscaras & Vermelho picante \\
Azaleia & Flamboyant & Festa da cereja \\
Fúcsia antiga & Vibrato & Bate coração \\
Rosa jardineira & Rosa exótico & Cereja intensa \\
Amor perfeito & Rosa angorá & Geleia de ameixa \\
Graciosa & Sorbet de cereja & Granadeiro \\
Berinjela profundo & Gelado & Uva francesa \\
Vinho do porto & Sweet baby & Escarlate \\
Veludo russo & Ameixa japonesa & Rosa savana \\
Fúcsia real & Vinho de mesa & Framboesa suave \\
Vermelho primoroso & & \\
\hline
\end{tabular}

Quadro 1 - recorte e discretização da cor vermelha

É certo que a subcategorização das cores é realizada tecnicamente com a ajuda de um programa de computador, o qual é capaz de recortar o espectro do vermelho de modo extremamente preciso e minucioso, oferecendo uma gama de subespectros bastante recortada - para falar em termos metafóricos, temos uma faca tecnológica grandemente afiada; mas precisamos ter em mente que este hiperrecorte é conduzido essencialmente por uma faca ideológico-axiológica, a qual recorta as cores básicas em dezenas de cores secundárias em função de interesses a serem atingidos.

No processo de rotulação dos subtipos de cores podemos perceber a ausência de traços descritivos e a preferência por associações com sentidos vinculados a lugares paradisíacos e/ou exóticos, a comidas e bebidas saborosas e requintadas; a culturas antigas, à natureza saudável e pura. Ou seja, as cores viram referentes constitutivamente e irremediavelmente vinculados a todo um sistema de crenças e valores positivos. O jogo é aquele típico da publicidade: iludir o consumidor de que a escolha de um produto, apresentado como especial, serviria para indicar que o sujeito que escolhe é quem é especial e único. Exagerando, é como se o espectro diversificado do catálogo de cores das lojas quisesse indicar a existência de uma cor para cada consumidor.

Para mencionar ainda outro exemplo, se formos observar como os psicólogos discretizam os tipos humanos segundo seu comportamento, também veremos saltar aos olhos uma miríade de categorias e tipologias. E poderemos, mais uma vez, ficar espantados com as dezenas, quiçá centenas, de doenças a que estamos sujeitos. 
ALVES FILHO, F. Funções axiológicas do recorte...

Esses exemplos todos apontam para um mesmo fenômeno cultural-ideológico: o mundo urbano-consumista atual procede a uma superabundante discretização dos fenômenos e referentes, de tal modo que poderíamos dizer que há hoje uma superpopulação de referentes nas cidades e nos espaços urbanos. Inflacionados, os referentes não somente são muitos como são de tipos enormemente variados. Trata-se, é claro, de uma evidência extremamente relevante para corroborar a tese da fabricação cultural e histórica dos referentes ${ }^{2}$.

Contudo, o ponto mais importante desta evidência é indagar-se por que razões convivemos em meio a uma superpopulação de referentes nos dias atuais. Numa primeira aproximação, diríamos que talvez devamos olhar o fenômeno por, pelo menos, dois pontos de vista: um empírico e outro discursivo, mas sem deixar de observar as mútuas influências que um exerce sobre o outro.

Do ponto de vista empírico, é evidente que o avanço tecnológico, com seus aparelhos bastante sofisticados para observar e analisar o mundo possibilitou ao homem enxergar discretizações e recortes antes impossíveis. Ou seja, a sofisticação tecnológica permitiu ao homem acesso a unidades da matéria cada vez menores, principalmente através de criação de imagens virtuais que promovem um recorte superespecializado das coisas do mundo. Blikstein (1990), com base em Shaff, defendeu que construímos os referentes com base em nossos óculos sociais. Entretanto, temos que acrescer que, interpondo-se aos óculos sociais, temos hoje também os olhos tecnológicos, os quais reproduzem virtualmente a realidade. Ou seja, fabricamos hoje os referentes mediados por variados tipos de óculos: além dos inevitáveis e inalienáveis óculos social-axiológicos, também podemos dispor de óculos virtuais. Por conta disso, entre nossos óculos sociais e a realidade temos a interposição de outra realidade (virtual, que simula a real) e os óculos tecnológicos, os quais fazem as vezes, embora parcialmente e de modo refratado, de nossos óculos cognitivos.

2 Um estudo interessante, motivado por este fenômeno, poderia observar a hiperdiscretização e hipercategorização dos referentes na sua correlação com a produtividade lexical, de modo a se responder perguntas do tipo: que processos lexicais têm sido mais produtivos para permitir essa hiperdiscretização de referentes? A hiperdiscretização referencial influenciou de que maneira nos processos lexicais de formação de palavras nas línguas atuais? Ou seja, este fenômeno parece indicar um campo de pesquisas fecundo envolvendo a interface entre teorias lexicais e teorias referenciais. 
Por outro lado, também é notável que o chamado fenômeno da globalização fez com que tivéssemos acesso a novos e diferentes referentes. Um exemplo típico deste fenômeno é o que ocorre com a culinária, seja quando olhamos para um cardápio seja quando nos aproximamos de uma buffet num restaurante self-service. De fato, há uma realidade empírica múltipla com a qual convivemos e correlatamente, claro, uma realidade linguístico-lexical também múltipla.

Contudo, estes fenômenos empíricos, tecnológicos e culturais não se constituem nem funcionam à margem dos sistemas linguísticos e ideológicos. Embora devamos reconhecer que a moderna tecnologia possa nos aproximar um pouco mais do real real, ainda assim permanecemos convivendo com uma refração desta realidade. $\mathrm{E}$ isso ocorre porque são nossos óculos sociais que leem a imagem virtual elaborada pelos óculos tecnológicos. Isto é, os óculos tecnológicos, bem como as imagens neles produzidas, são vistos por nossos óculos sociais.

Essa superabundância referencial, como não poderia deixar de ser, também apresenta consequências cognitivas, pelo fato de haver exigência maior - no sentido de mais diversificada - de reconhecimento referencial. Ou seja, há uma diversidade maior de objetos empíricos e de rótulos nominais que precisamos, se assim quisermos, apreender. Como há mais referentes a serem reconhecidos e como é cada vez mais difícil dar conta de tamanha tarefa, isso pode gerar uma espécie de frustração cognitiva.

Vamos levantar aqui algumas hipóteses embrionárias para os efeitos deste superpovoamento referencial.

O primeiro deles é que a subespecificação de referentes visa criar um efeito de subespecificação também dos sujeitos, para dar a entender a possibilidade de que cada sujeito possa se imaginar como único, como diferentes dos demais, portanto imaginariamente possuidor de um estilo próprio. A profusão referencial de estilos musicais, tipos de roupa e corte de cabelo, por exemplo, visa atingir meio que metonimicamente os próprios sujeitos. Se disponho apenas de dois tipos de calças, aparentemente, sou igual a milhões de pessoas; mas se existem 50 categorias de calças, há muito mais chances de eu, ainda que imaginaria e ilusoriamente, ser diferente dos meus pares. É bem evidente que há um interesse comercialconsumista por trás de tamanha hiperdiscretização dos referentes do mundo: na medida em que as indústrias oferecem variados subtipos de produtos, elas criam o efeito no consumidor de que algum desses produtos foi feito especialmente para ele, consumidor, que se encontra diante de uma prateleira real ou virtual. No exem- 
ALVES FILHO, F. Funções axiológicas do recorte...

plo das cores comentado acima, isso é bem evidente porque os 41 tipos de vermelho aparecem discretizados num site de uma empresa que vende tintas para decoração de interiores.

\section{Extensão referencial axiológica em editoriais de jornal}

Nosso segundo material de análise consiste de editoriais de jornais brasileiros, em que investigamos especificamente como se dá a fabricação referencial de entes humanos. A noção de extensão da semântica clássica de base lógica (cf. van DIJK, 1977; LYONS, 1979) procurava explicar que segmentos da realidade fazem parte da referência dos termos linguísticos. Esta teoria esbarrou em duas limitações quando se imaginava aplicá-la para explicar textos reais: a noção de vericoncionalidade - os referentes precisam existir de verdade e corresponder "verdadeiramente" aos segmentos linguísticos; e noção de referente empírico - os referentes deveriam existir num mundo empírico. Tais limitações fizeram com que a noção de extensão fosse abandonada ou negligenciada nos estudos da referenciação mais recentes.

Nosso intuito aqui é buscar recuperar a noção de extensão, mas vendo-a por um ponto de vista ideológico e axiológico. Nosso argumento para recuperá-la reside no fato de que muitos textos visam direcionar a atenção do interlocutor para uma realidade empírica e, para isso, operam uma discretização do mundo. Entretanto, isso precisa ser visto não como um traço da empiria dos próprios objetos ou como um critério de uma suposta vericondicionalidade da referência. Não se trata disso, porque a extensão dos referentes (ou seja, sua existência como um único referente, um subconjunto de um conjunto de referentes ou como um conjunto inteiro) é elaborada nos textos segundo índices de avaliação e apreciação axiológica. Dito de outro forma, há interesses guiando o tipo de extensão pretendido para enquadrar certo referente. Dito isso, vamos apresentar um conjunto de categorias de marcação extensional para referentes que comumente figuram em editoriais (para outros gêneros há que se proceder a outras análises por que nossa hipótese geral é de que este recorte é fortemente orientado pelos gêneros do discurso).

Identificamos os seguintes modos de recorte dos referentes em editoriais de jornal: 
a) Recortado como único e particularizado como membro de um conjunto de referentes com os quais ele comunga traços. Ele é presumido como existente, mas não identificado pelo autor. Aqui o texto deixa muito claro que o referente existe em algum mundo possível, ou seja, há uma presunção ontológica a seu respeito. Além disso, ele é apresentado em seu caráter de unicidade, ou seja, como um membro, discretizado em relação aos outros. Entretanto, o locutor, por diversas razões, não o identifica direta e explicitamente. Tomemos o exemplo seguinte.

(1) (...) Sabendo-se o papel que a merenda escolar desempenha no regime alimentar dessas crianças (quase todas as crianças estão na escola), seria crueldade excluir uma só delas da escola por questões de desempenho. Mas a promoção automática equivale, na prática, a deixar um doente privado do uso do termômetro. ("A grande esfinge", O Globo, 30/11/2002).

Tudo indica que o editorial não considera relevante identificar a qual criança se refere diretamente, embora indique que pretende referir uma única criança presumidamente existente. Em termos estritamente informativos, poderia ser qualquer uma delas, mas não deixa de ser sintomático o fato de que se está falando de crianças pobres, moradoras de periferia e estudantes da escola pública brasileira, portanto, sem reconhecimento social.

Já o exemplo seguinte, o qual também apresenta um referente como presumidamente existente e único mas não identificado, o faz por outras razões. Trata-se de uma estratégia para se eximir de criticar abertamente o comportamento de um parlamentar. O editorial faz isso ao se recusar a usar o nome próprio - estratégia linguística que identificaria o referente no cenário social e político - do parlamentar cujo comportamento está sendo analisado.

(2) (...) Um dos parlamentares, de forma exaltada, foi à tribuna para protestar contra a redução do auxílio-combustível, que caiu de $\mathrm{R} \$ 15$ mil para pouco mais de $\mathrm{R} \$ 4,5$ mil. Segundo ele, a imprensa sempre passa uma imagem negativa do Congresso e quer monitorar a ação dos deputados e senadores. Ele disse que a imprensa quer implantar a sua própria ditadura. Há outra ditadura no Brasil? Ainda conforme o mesmo parlamentar, daqui a pouco a imprensa vai querer que a gente venha para a Câmara de bicicleta. Claro que o referido deputado não tem razão em pronunciar tamanho disparate, até porque a imprensa não faz outra coi- 
ALVES FILHO, F. Funções axiológicas do recorte...

sa a não ser divulgar os fatos. Para que estes fatos sejam divulgados, é preciso que sejam gerados. E eles são gerados na própria Câmara. ("Prerrogativas e atribuições", Meio Norte, 28/4/2006)

O interessante do editorial é que a opção por referir um ente discreto da cena política, mas sem identificá-lo explicitamente, está a serviço de duas posturas adotadas pelo jornal: cumprir o papel de fazer críticas à vida política, ainda que superficialmente, mas, ao mesmo tempo, sem indicar culpados, eximindo-se de atacar diretamente as figuras dos altos escalões de poder. O jornal se esquiva de ser o autor do ato de referenciação direta, evitando desagradar o sujeito referido. Tudo seria bem diferente se o referente fosse identificado, por exemplo, com o uso de nomes próprios, pois, neste caso, o jornal estaria assumindo a responsabilidade direta e inequívoca de referir um ente, recortando e identificando-o. Esse caso ajuda a esclarecer que o ato de referir não coincide exatamente com a ação de identificação dos referentes, de modo que é possível referir identificando ou não.

\section{b) Recortado como único, existente e diretamente identificado pela expres-} são referencial. Aqui há indícios de que o locutor deseja que o seu interlocutor compreenda o texto identificando em algum mundo este referente único. $O$ recurso linguístico-lexical mais apropriado para este uso é o uso de nomes próprios tomado aqui no sentido usado pela gramatical normativa e não na acepção da filosofia da linguagem. Ao usar o nome próprio, o locutor assume e se responsabiliza tanto pelo recorte como pela identificação do referente.

Mas é claro que esta identificação do referente pode ser realizada por outros recursos léxico-gramaticais (descrições definidas, descrições indefinidas, descrições demonstrativas), sobretudo numa análise de um texto integral em que é possível acompanhar as cadeias referenciais. Esse modo de recortar o referente pode ser lido do ponto de vista ideológico observando-se a atitude valorativa e axiológica presente no texto. Caso se trate de um texto que avalia negativamente o referente, a forma de referir indica que o editorial pretende atingir diretamente a imagem do referente. Ou seja, a forma de referir contribui para consolidar esta avaliação. Caso se trate de um texto que avalie positivamente, a opção de referi-lo como único e identificado também consolida esta avaliação. Vejamos alguns casos.

(3) Existe enorme torcida pela Varig. E é mais do que natural. Há 75 anos, a companhia aérea fundada por Ruben Berta ajuda a difundir a imagem 
do país. Suas agências nas grandes capitais cumprem função diplomática, fazem as vezes de embaixada e consulado. Na verdade, é razão de orgulho para os brasileiros verem a Bandeira nacional na fuselagem cuja marca registrada é a rosa dos ventos. Por mais aguda que seja a atual crise financeira, o sentimento de forte identificação não será abalado. ("Luz no horizonte", Jornal do Brasil, 2 de dezembro de 2002)

(4) Ao aprovar, ontem, o projeto do senador e ex-presidente José Sarney que permite a instalação de Zonas de Processamento e Exportação (ZPEs), a Comissão de Assuntos Econômicos (CAE) do Senado abriu caminho para o que poderá vir a ser uma revolução na economia do Brasil e, ao mesmo tempo, corrigiu um equívoco que retardou a entrada do país na economia globalizada. (“A vitória da perseverança”, O Estado do Maranhão, 20 de junho de 2007)

(5) Se valessem só os planos de governo, habitantes da maior metrópole do país estariam a caminho do paraíso atmosférico e climático. Na prática, contudo, as boas intenções são substituídas por emissões que só pioram o efeito estufa e a saúde da população ("Cortina de fumaça", Folha de São Paulo, 3/9/2008)

(6) O Banco do Brasil (BB) errou ao retirar da mostra "Erótica - Os Sentidos da Arte" o trabalho da artista Márcia X (1959-2005) que retratava dois pênis desenhados com terços religiosos. Ninguém obriga o BB a patrocinar eventos artísticos, muito menos exposições polêmicas como "Erótica", cujo insofismável teor sexual está anunciado no título. (“Arte crucificada", Folha de São Paulo, 29 de abril de 2006)

No exemplo (3) o referente Varig é identificado explicitamente com o uso do nome próprio correspondente, num editorial que avalia positivamente o referente Varig. O que interessa neste caso é observar que é comum na imprensa brasileira, quando se trata de avaliações negativas sobre empresas privadas, omitir-se o nome próprio do referente que está sendo avaliado. Isto é, a escolha da forma de referir indicia um evidente comportamento ideológico da grande imprensa brasileira, qual seja, proteger a face das empresas privadas. O exemplo (4) pode ser interpretado de modo bem semelhante ao que aplicamos ao exemplo (3), com a diferença de que ele refere e identifica ao mesmo tempo um político brasileiro, o qual é aqui avaliado de modo positivo. Esta dupla função de referir e identificar explicitamente 
ALVES FILHO, F. Funções axiológicas do recorte...

é regularmente realizada por editoriais brasileiros, de modo ainda mais recorrente nos jornais de pequenas e médias cidades. Uma comparação com o exemplo (2), cujo referente é um político brasileiro (um parlamentar), mas avaliado negativamente, ilustra bem como os modos de referir com ou sem identificação indicia inequivocamente a tomada de posição político-ideológica da imprensa.

Já o exemplo (5) evidencia a possibilidade de, mesmo sem o uso de nome próprio, no caso a maior metrópole do país, ser possível identificar prontamente o referente, embora tal identificação se encontre na dependência do saber enciclopédico do leitor. A descrição definida a maior metrópole do país indica que existe apenas um referente possível de ser a ela associado porque se trata de uma descrição construída através de uma comparação de superioridade, a qual indicar haver somente um referente com as características descritas. Ademais, a descrição $a$ maior metrópole do país para referir a cidade de São Paulo é usada largamente na imprensa e, indubitavelmente, dado o perfil do leitor de editorial, faz quase nenhuma diferença referir a capital de São Paulo como São Paulo ou como a maior metrópole do país. Mas vejamos que se trata de um uso bem diferente do que ocorreu com o exemplo (2), em que a possibilidade empírica de referentes do mundo real serem associados à expressão referencial um dos parlamentares é muito grande. Para descobrir a qual referente real pode ser associada esta expressão não basta conhecimento enciclopédico geral, mas seria necessário ter assistido à transmissão da sessão da Câmara dos Deputados em que ocorreu o pronunciamento ou estado lá. Vê-se como a estratégia é mesmo útil para o jornal não se esquivar da crítica que pretendia fazer.

No exemplo (6) temos a coincidência entre referir, identificar diretamente o referente e avaliá-lo negativamente. O referente Banco do Brasil é designado pelo seu nome próprio e não por, como poderíamos hipotetizar com base no comportamento dos editoriais, por um banco brasileiro, o maior banco público brasileiro, casos que indicariam outra postura do jornal. Ao usar a expressão referencial $O$ Banco do Brasil, o jornal Folha de São Paulo não delega aos seus leitores a tarefa de, com base em seu conhecimento enciclopédico, identificar o referente, mas toma-a para si mesmo. Quão bom seria para nós, leitores, se este comportamento da Folha de São Paulo fosse um padrão para todas as instituições referidas, fossem elas públicas ou privadas.

c) Recortado como uma categoria teórica, suposta, hipotética. Os estudos de semântica clássica referiram-se a esse uso como atributivo, para dizer que não 
estava em jogo referir um ente específico (isso se dava porque os estudos reservavam a referência para as coisas empíricas). Do meu ponto de vista, há sim uma referência, mas ela é feita a uma entidade tomada em termos conceituais e hipotéticos, isto é, refere-se a uma condição de existência.

(7) Sabendo-se o papel que a merenda escolar desempenha no regime alimentar dessas crianças (quase todas as crianças estão na escola), seria crueldade excluir uma só delas da escola por questões de desempenho. Mas a promoção automática equivale, na prática, a deixar um doente privado do uso do termômetro. ("A grande esfinge", O Globo, 30/11/2002).

(8) A teoria atual é a dos ciclos: leva-se o aluno até o fim de um ciclo (no caso, de quatro anos) para ver se ele tem condições de entrar no ciclo seguinte. Enquanto isso, passaram-se quatro anos; e quando chega o momento crucial de passar da quarta para a quinta série, o desapontamento pode ser total. A criança não tem condições de passar para o ciclo seguinte. E assim entram em ação os condicionamentos fatais como o fenômeno que se chama evasão escolar. ("A grande esfinge", O Globo, 30/11/2002).

Nos exemplos anteriores, quando se diz um doente, faz-se referência à condição de estar doente e quando se enuncia o aluno, faz-se referência à condição se ser aluno. Veja-se que, em casos como estes, as noções de significação e referência se aproximam, embora ainda se possam manter as suas diferenças. Ou seja, aqui a referência de um doente equivale a uma escolha real num enunciado real de uma categoria do mundo hipotético e não às possibilidades de sentido dicionarizadas. Precisamos admitir que podemos referir tanto objetos empíricos, como hipotéticos, abstratos, sonhados, imaginados, desaparecidos, etc. Manter a distinção entre uso referencial e uso atributivo equivale a aceitar a pressuposição da referência restrita a referentes empíricos, o que não nos parece adequado. Melhor fazer uma correlação entre referência e uso real da linguagem e sentido a sua virtualidade semântica.

d) Recortado como parte de um referente ou como um subconjunto de referentes. Neste caso, refere-se a elementos tomados ou partitivamente ou como um subconjunto de um conjunto maior e opera-se um processo enunciativo de inclusão e exclusão, isto é, abertamente diz-se que se está a referir apenas uma 
ALVES FILHO, F. Funções axiológicas do recorte...

parte dos referentes de uma classe e que outra parte está excluída do ato de referenciação. O que é relevante, do ponto de vista discursivo, para estes casos é que esta é uma estratégia para evitar generalizações. Vejamos um exemplo:

(9) Governos novos enfrentam problemas novos e antigos. Também ao governo Lula caberá a esfinge da educação - que vai nos devorar se não for decifrada, ou tirada do caminho. O governo que sai tem números positivos a mostrar nesse terreno - sobretudo a quase universalização da educação pública para o ensino fundamental. Mas são construções ainda muito frágeis. Dizer que quase todas as crianças estão na escola é apenas o ponto de partida para o desafio seguinte - o de dar um mínimo de qualidade a esse ensino. É verdade, quase todas as crianças estão na escola. Mas a política da promoção automática, adotada desde 1997 no ensino público, criou tanto problemas quanto soluções. ("A grande esfinge”, O Globo, 30/11/2002)

No exemplo (9) o editorial do jornal O Globo faz-se referência à quase universalização da educação pública para o ensino fundamental e a quase todas as crianças, e não à universalização da educação pública para o ensino fundamental e a todas as crianças. O quantificador quase tanto orienta o leitor para identificar o referente entendendo-o como parcial e não como total, como também cumpre a função de relativizar um ponto de vista demasiado otimista. Por se tratar de um editorial que contém avaliações positivas acerca do governo FHC, esse modo de referir serve para atenuar uma tomada de posição, podendo servir também para indicar que o jornal tem uma visão equilibrada e ponderada dos fatos. Dizer que houve total universalização da educação pública ou negá-la inteiramente poderiam ser tomadas como posturas radicais, impensadas, cegas.

e) A classe de todos os referentes de um dado conjunto. Neste caso, a expressão referencial é escolhida para mencionar a classe inteira de um conjunto de referentes, não deixando de fora nenhum de seus referentes individuais. Apresentamos dois exemplos na sequência:

(10) Há, portanto, um imenso trabalho a ser feito. Por exemplo, há que motivar os professores, peça fundamental do sistema. A categoria sofreu tantos abalos, experimentou tanto desprestígio, que se tornou às vezes massa de manobra para cabeças quentes. Greves começam a qualquer hora - como se o professor quisesse vingar-se da sua situ- 
ação; duram muito tempo sem que isso tenha resultado prático. Quem paga a conta, claro, é o aluno. Como falar, nesses termos, em projeto pedagógico? ("A grande esfinge”, O Globo, 30/11/2002).

(11) A violência no Maranhão atingiu seu nível máximo nos últimos dias. Assombrada e perplexa com o cotidiano de assaltos e homicídios diários, muitos dos quais cometidos com traços de barbárie, a população agora se depara com a moda do sequestro, que parece importada dos grandes centros. No contraponto uma polícia disposta e experiente, mas carente de um comando ativo e eficiente. No centro do furacão, uma cúpula que titubeia na definição de uma política de segurança cujos pilares ainda não foram devidamente explicados e que só se sustenta no viés cidadão, que mais parece arranjado de marketing do que um objetivo a ser alcançado. ("Violência agravada", O Estado do Maranhão, 21/06/07)

No exemplo (10) as descrições definidas os professores e a categoria visam referir todo o conjunto de professores brasileiros, mas isso somente pode ser percebido com a leitura do texto integral. Ou seja, da forma como está formulado o texto, fica claro que as duas descrições desejam designar todos os elementos de um conjunto, embora ainda fique a cargo do leitor decidir, entre muitos grupos possíveis de professores, qual deles está em jogo aqui, por exemplo, todos os professores do mundo? Todos os professores de escolas públicas? Do Ensino Básico? A questão central aqui é se perguntar se, de fato, todos os elementos deste grande conjunto de professores sentem-se "desmotivados, desprestigiados e se tornou às vezes massa de manobra para cabeças quentes", como predica o editorial. Isso indica que referir toda uma classe de referentes, estendendo a todos os seus elementos determinadas predicações, pode resultar numa generalização que refrata imensamente a realidade na medida em que estende ao conjunto inteiro de referentes atributos e características que podem não ser pertinentes a todos (pode ser polêmico o seu pertencimento).

No caso do exemplo (11), ao se atribuir a predicação agora se depara com a moda do sequestro, que parece importada dos grandes centros a toda a população de São Luís do Maranhão, faz-se uma generalização passível de bastante questionamento pelo fato, improvável do nosso ponto de vista, de que todos os membros da população de São Luís estejam sendo vítimas de sequestro. Já dar 
ALVES FILHO, F. Funções axiológicas do recorte...

para ter uma ideia de como fabricar um referente como sendo toda uma classe pode visar convencer o interlocutor a respeito de uma realidade com um alto grau de refração.

Tomando por base a discussão teórica e a análise aqui realizada, podemos dizer que existem as seguintes funções enunciativas para a demarcação fabricada da extensão dos referentes:

a) evitar comprometer-se com uma crítica direta e explícita a um ente singular ou assumir uma crítica direta e explícita a um ente singular;

b) fazer coro a e contribuir para legitimar um discurso generalizante, que dificulta enxergar as particularidades, contradições, diversidade múltipla e complexidades dos fenômenos;

c) conferir um tom de verdade ao que é dito, através da generalização daquilo que é singular e particular;

d) particularizar aquilo que é coletivo e plural, de modo a que indivíduos e instituições sejam reconhecidos por um feito que não lhes merece de direito;

e) no campo do consumo, servir como argumento para a ideia da multiplicidade e variedade de opções e de condutas, contribuindo para aumentar o consumo de produtos que, supostamente, atestam uma miríade de atitudes diferenciadas entre as pessoas.

\section{Considerações finais}

Neste trabalho foi possível revisitar e, ao mesmo tempo, fazer um deslocamento teórico da noção de extensão referencial, de modo a observá-la por um ponto de vista enunciativo. $\mathrm{O}$ estudo aponta para a ideia de que a extensão dos referentes é uma noção relevante para a compreensão do processo de referenciação, mas desde que ela seja vista não como uma empiria, mas como uma construção discursiva. A análise do recorte e da discretização de referentes de diversas esferas da atividade humana (comércio, psicologia, música, internet) corrobora a tese de Blikstein (1990) de que os referentes são fabricados segundo os corredores isotópicos decorrentes da práxis humana. Já a análise da extensão referencial em editoriais de jornal indica que há uma grande variedade de processos enunciativos para discretizar e identificar os referentes, as quais podem se prestar a fins argumentativos. 


\section{Agradecimentos}

Agradeço à FAPEPI pelo apoio à realização da pesquisa que deu subsídio a este artigo.

\section{Referências}

ALVES FILHO, F. Referenciação e dialogismo: aproximações e distanciamentos. Trabalho apresentado no congresso Abralin em Cena. Teresina: UFPI, 2008 (inédito). BLIKSTEIN, I. Kaspar Hause ou a fabricação da realidade. São Paulo: Cultrix, 1990.

FREGE, G. Translations from the philosohical writings. GEACH, P.; BLACK, M. (Org.). Oxford: Basil Blackwell, [1898]1975.

ILARI, R. Anáfora e correferência: por que as duas noções não se identificam? Caderno de Estudos Linguísticos, Campinas, n. 41, p. 91-109, jul/dez 2001.

KOCH, I. V. Desvendando os segredos do texto. São Paulo: Cortez, 2001. . Referenciação e orientação argumentativa. In: KOCH, I. V, MORATO, E. M.; BENTES, A. C. (Org.). Referenciação e discurso. São Paulo: Contexto, 2005, p. $33-52$.

LYONS, John. Introdução à linguística teórica. São Paulo: Nacional, 1979.

MARCUSCHI, L. A. Anáfora indireta: o barco textual e suas âncoras. In: KOCH, I. V.; MORATO, E. M.; BENTES, A. C. (Org.). Referenciação e discurso. São Paulo, Contexto, 2005, p. 53-101.

MILNER, J. C. Reflexões sobre a referência e a correferência. In: CAVALCANTE, M. M.; BIASI-RODRIGUES, B.; CIULLA e SILVA, A. (Org.). Referenciação. São Paulo: Contexto, 2003, p. 85-130.

MONDADA, L.; DUBOIS, D. Construção dos objetos de discurso e categorização: uma abordagem dos processos de referenciação. In: CAVALCANTE, M. M.; BIASIRODRIGUES, B.; CIULlA e SILVAA. (Org.). Referenciação. São Paulo: Contexto, 2003, p. 17-52.

VAN DIJK, T. A. Text and context: explorations in the semantics and pragmatics of discourse. Londres e Nova York: Longman, 1977. 
ALVES FILHO, F. Funções axiológicas do recorte...

\begin{abstract}
This presentation aims at discussing the role of the referential processes to promove the discretization and the categorization of the objects of the several worlds when they change them in discourse objects. The investigation required going back to the notion of extension in order to make a theoretical dislocation and treat it as an enunciative phenomenon. Taking that into account, the main thesis of this work is that the discretization and categorization of the world operation is motivated by the subjects' axiological evaluations and causes, mainly, a refraction of such objects, once the same object can be shown in a lot of ways when they are motivated by several discursive intentions. The analysis offers very significant signs so that one can think that the relation between the world and discourse objects, far from being biunovocal and vericonditional, is mainly a socio-ideological one.
\end{abstract}

Keywords: reference; categorization; editorial; axiological evaluation. 